\title{
LALINET NETWORK STATUS
}

Eduardo Landulfo $^{1^{*}}$, Albeht Rodríguez Vega ${ }^{2}$, Alexandre Calzavara Yoshida ${ }^{1,3}$, Alvaro Bastidas ${ }^{4}$ Amanda Vieira dos Santos ${ }^{5}$, Antonieta Silva ${ }^{6}$, Antonio Arleques Gomes ${ }^{1}$, Boris Barja Gonzalez ${ }^{7}$ Carlos Andrés Melo-Luna ${ }^{9}$, Carlos D. Hoyos ${ }^{9}$, Cristina Tobler de Souza Rae ${ }^{10}$, Daniel Camilo ${ }^{10}$, David Vivas ${ }^{9}$, Diego Alves Gouveia ${ }^{5}$, Elian Wolfram ${ }^{11}$, Estela Collini ${ }^{12}$, Fábio J. S. Lopes ${ }^{1}$, Gregori de Arruda Moreira ${ }^{1}$, Henrique de Melo Jorge Barbosa ${ }^{5}$, Hernan Ciminari ${ }^{12}$, John H. Reina ${ }^{9}$, Jonatan João da Silva ${ }^{1}$, Jonnathan Céspedes ${ }^{9}$, Juan Carlos Antuña Marrero ${ }^{2}$, Juan Luis Guerrero Rascado $^{14}$, Juan Pallotta ${ }^{11}$, Judith Hoelzemann ${ }^{10}$, Lucas Alados Arboledas ${ }^{14}$, M.Alejandra Salles ${ }^{12}$, Marcos Paulo Araújo da Silva ${ }^{10}$, Renata Sammara ${ }^{10}$, Ricardo N. Forno ${ }^{13}$, Sebastian Papandrea ${ }^{12}$

${ }^{l}$ Center for Lasers and Applications, Nuclear and Energy Research Institute, Av. Prof. Lineu Prestes, 2242, São Paulo, Brazil ${ }^{2} G O A C$ (INSMET/CUBA) - Cuba

${ }^{3}$ Instituto de Ciências Exatas e Naturais do Pontal, Universidade Federal de Uberlândia, ICENP/UFU Ituiutaba, MG, 38304-402 - Brazil

${ }^{4}$ GLEO-UNALMED - Colombia

${ }_{5}^{5}$ Instituto de Física, Universidade de São Paulo, Rua do Matão 1371, São Paulo, SP, 05508-090, Brazil

${ }^{6}$ Departamento de Ciencias Físicas, Universidad de La Frontera, Temuco - Chile

${ }^{7}$ Atmospheric Research Laboratory (LIA), University of Magallanes (UMAG). Av. Bulnes 01855, 6210427, Punta Arenas - Chile

${ }^{8}$ Universidad Nacional de Colombia - SIATA (AMVA) - Colombia

${ }^{9}$ Centre for Bioinformatics and Photonics (CIBioFi), Universidad del Valle, Calle 13 No. 100-00, Edificio E20 No. 1069, 760032 Cali - Colombia

${ }^{10}$ Departamento de Ciências Atmosféricas e Climáticas - Universidade Federal do Rio Grande do Norte (DCAC/UFRN) - Brazil

${ }^{11}$ Unidad de Investigación y Desarrollo Estratégico para la Defensa. Juan Bautista de la Salle 4397, Villa Martelli, Buenos Aires, Argentina CP:B1603ALO

${ }^{12}$ National Meteorological Service (SMN), Av. Dorrego 4019, CABA, Argentina CP: C1425

${ }^{13}$ Laboratorio de Física de la Atmósfera, Universidad Mayor de San Andrés (UMSA), Campus

Universitario Calle 27 de Cota-Cota, La Paz Bolivia

${ }^{14}$ Andalusian Institute for Earth System Research (IISTA-CEAMA), University of Granada, Autonomous Government of Andalusia, Granada, 18006, Spain

${ }^{15}$ Department of Applied Physics, University of Granada, 18071, Granada, Spain

*Email: elandulf@ipen.br

\begin{abstract}
LALINET (Latin American Lidar Network) follows its goal to consolidation as a federative lidar network to provide regional coverage over Latin America in providing aerosol and greenhouse gas profiles following QA/QC protocols and promoting the development of researchers and students in atmopheric science field. We show recent results on different approaches for studying the optical properties of the atmosphere regarding aerosols at tropospheric and stratospheric level and greenhouse gas mixing ratio profiles followed by our recent support and validation efforts towards present and future satellite missions.
\end{abstract}

\section{INTRODUCTION}

LALINET became operational as a scientific network in 2013[1], as a member of GALION (GAW Lidar Observation Network) and covers mostly of South America and Central America. The scientific drives rely on observation of aerosol related events such as biomass burnings [2], volcanic eruptions [3], dust transport [4], aerosol-cloud interaction [5], as well GHG mixing ratio profiles [6] and related activities [7]. The majority of observations are at tropospheric level but strospheric observations are also available during special operation cycles. There are also efforts towards an algorithm consolidation following the strategy and goals of a robust 
database creation. As part of network organization a biannual workshop has been strictly followed in order to improve the network operational ability, to establish new scientific goals, to add more member stations to the network and foster education in atmospheric science.

\section{METHODOLOGY}

\subsection{Network Stations and lidar systems}

At the present there are 19 stations in LALINET, and 3 more proposed. They operate mostly with Nd:YAG laser typical wavelengths (1064, 532 and $355 \mathrm{~nm}$ ) and some with Raman and or polarization detection capability, there is also one station for $\mathrm{O}_{3}$ detection (RGL). Colocated with the lidar systems are sunphotometers, nearby radiossounding stations and other instruments.

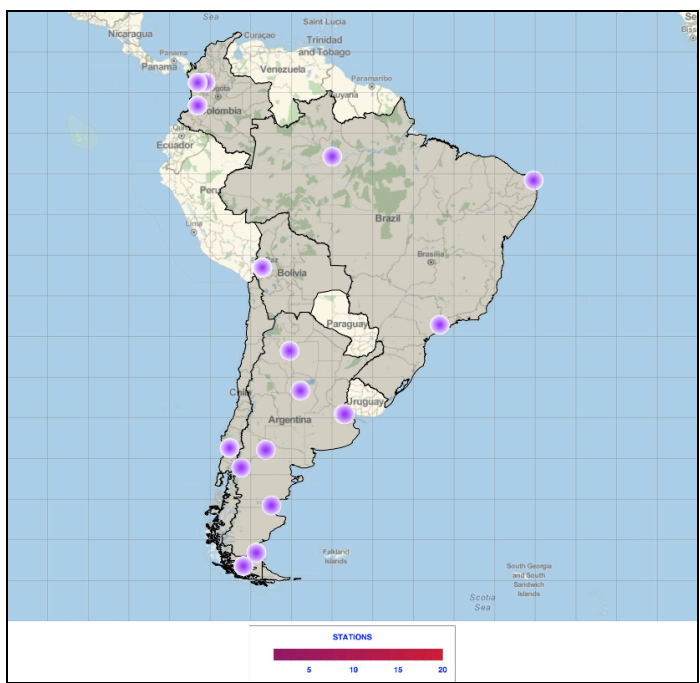

Fig. 1 Lidar Station sites in LALINET. There are centres involved in data analyis in the network.

The schedule for operation is on Mondays and Thursdays but given the spread of the station along the continent this is not a tight contraint for measurements and preferably one run under coordinate condition only during extreme events such larg biomass burning activities, dust outbreaks and volcanic eruptions.

\section{RESULTS}

\subsection{Tropospheric aerosols}

Tropospheric aerosols are measured in all stations of LALINET, showing different aerosol type contributions to the sites. Long term monitoring has been conducted in PAR site, located in pristine environment of the Southern - hemisphere midlatitude. Usually clean and pristine conditions prevail at this site, but occasionally dust and biomass burning aerosol layers were observed [xx]. Figure 2 shows the attenuated backscattered coefficient for $1064 \mathrm{~nm}$ channel (upper panel) and the volume depolarization ratio for $532 \mathrm{~nm}$ (bottom panel) during two days of measurements at PAR during November 27 to 29, 2018.

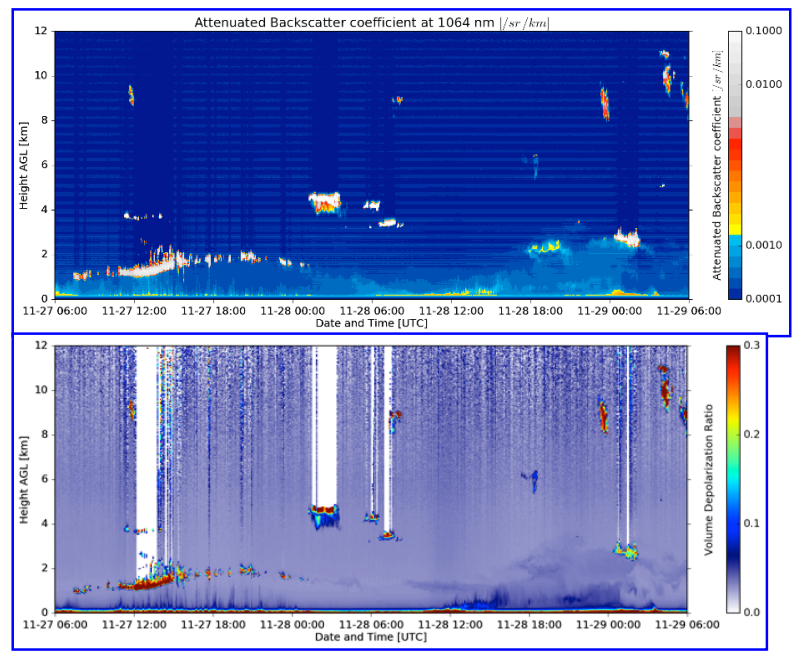

Fig 2. Attenuated Backscatter Coefficient for $1064 \mathrm{~nm}$ and Volume depolarization ratio for $532 \mathrm{~nm}$ at PAR station.

\subsection{Stratospheric aerosols}

A recent paper reports a multi instrument observational study of the aerosols from the April 2015 Calbuco volcanic eruption in Chile $\left(41.33^{\circ} \mathrm{S}\right.$, $72.62^{\circ} \mathrm{W}$ ). Combining the lidar and AERONET sun-photometer local at São Paulo, with MODIS, CALIPSO and OMPS LP the mean features of the UTLS aerosols transported over São Paulo were characterized. It was relevant the good agreement between the measurements from different instrument. In the case of coincident profiles of São Paulo lidar and OMPS_LP, the disagreement found was explained by the inhomogeneity of the UTLS aerosol layer [3]. LALINET is also coordinating its contribution to VOLRES (Volcanic Response), an initiative from SSiRC (Stratospheric Sulfur and its Role in Climate) a SPARC activity. Locations hosting LALINET lidars were evaluated to be fitted for balloon and sounding launching following technical requirements. Six potential LALINET 
sites has been identified: NQN, BRC, VMA, SMN, SPU and PAR, thus preparing Latin America to respond to large volcanic eruptions [8].

\subsection{Clouds}

Intensive measurement campaign in different stations allowed to identify cirrus clouds over a delimited height range between 7.0 to $18.0 \mathrm{~km}$ where they generally ocurred. Geometrical and optical properties allow a primary classification based on the average base and top of cirrus clouds and accounted their morphologial variety. Collocated data from radiosounding lauchings were used to observe relative humidity profiles.

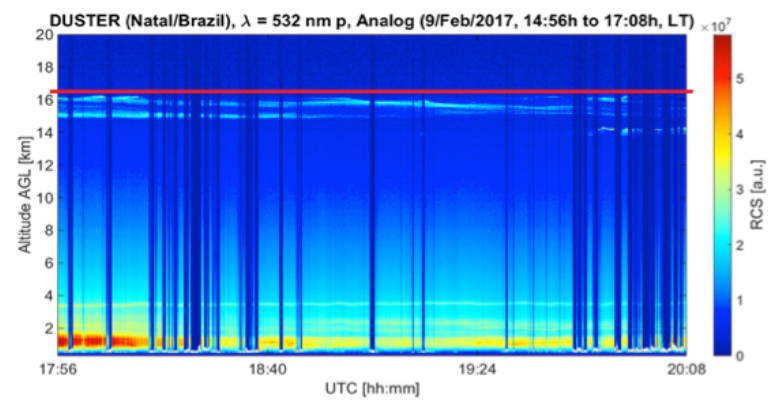

Fig 3. Cirrus cloud observation at NAT station. The presence of low clouds made a special operation schedule to be performed.

It has been derived also the first comprehensive statistics of optical and geometrical properties of cirrus clouds in Amazonia and estimates of its radiative forcing. For that, 1 year of ground-based lidar observations in the central Amazon forest, Brazil. The retrieved optical and geometrical properties (published by [5]) were then considered to calculate the cirrus radiative forcing (CRF) and heating rates profiles computed in detail by the radiative transfer models. The MAO cirrus frequency of occurrence was found to be as high as $88 \%$ during the wet season and not lower than $50 \%$ during the dry season, with mean values of cirrus cloud top and base heights, cloud thickness and cloud optical depth were $14.3 \pm 1.9$ (std) km, $12.9 \pm 2.2 \mathrm{~km}, 1.4 \pm 1.1 \mathrm{~km}$, and $0.25 \pm 0.46$, respectively. With such high frequency of occurrence and altitude over the dark-pristine Amazon forest (albedo $\alpha \approx 0.12$ ), these clouds produced a net $\mathrm{CRF}$ at the top and bottom of the atmosphere (TOA and BOA) of +14.7 and -3.6 $\mathrm{Wm}-2$, respectively. Together, the vertical profiles with total optical depth (column integrated COD)
$>0.3$ was responsible for about $72 \%(62 \%)$ of the TOA(BOA) net CRF.

\subsection{Greehouse gas profiles $-\mathrm{O}_{3}$}

Height-resolved ozone measurements over RG station Gallegos were measured with a differential absorption lidar (DIAL) instrument. Llidar profiles are carried out in November 2009 have a duration that ranges from $3-5 \mathrm{~h}$. Ozone densities as a function of altitude for selected days are shown within a dynamic range from 14.5 to 45 $\mathrm{km}$. An austral $\mathrm{O}_{3}$ climatology in mixing ratios was possible together with satellite and ozonesonde observations during the 1980-1991 period and is available for 17 latitudinal bands from 80 to 80 degrees spacing at 17 pressure levels between 100 and $1 \mathrm{hPa}$. Complete description a this atmospheric event intrusion of polar airmass with depleted ozone content over RG station can be found in Wolfram el al [9].

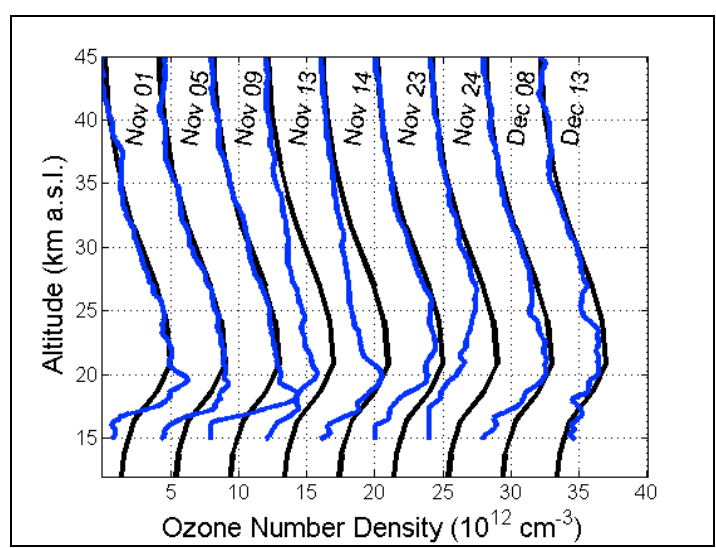

Fig 4 Lidar ozone profiles measured in Rio Gallegos sites (blue lines) from 1 November to 13 December 2009.

\subsection{Planetary Boundary Layer}

The PBL Height estimation methods in the network database are performed from several algorithmsIn the last five years many campaigns about validations of proposed methodologies have been performed. Among them, the MCity Campaign stands out, due to comparison between radiosonde and lidar data performed during 20 days consecutively (figure The micrometeorological studies are concentrated in the analysis of high-order moments (until fourth order) from elastic lidar data. A good example is presented from Cali Station [20] in Colombia where GM and WCT methods are employed. 


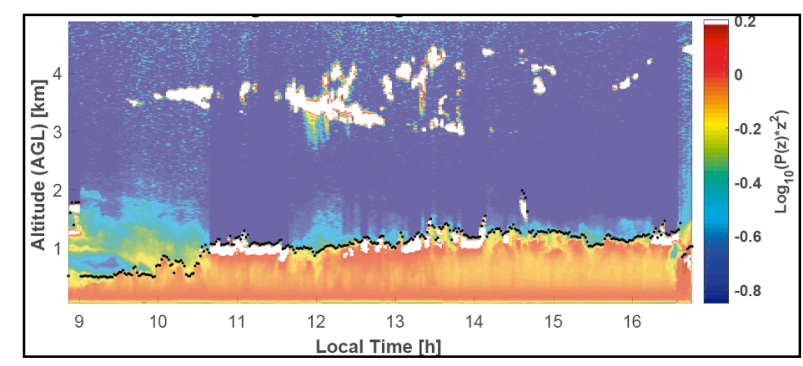

Fig 4. Cali Station temporal evolution of range corrected signal in the period 08:30 - 17:00 December 13th, 2018. The scatter plot represent PBL top.

\subsection{Satellite validation}

In order to support present and future satellite mission LALINET is working on increase the accuracy of aerosol measurements and improve the network observation capability by the implementation of more rigorous and systematic protocols. The ultimate goal is to develop a robust database of the vertical distribution of aerosols over South America. The more recent effort is LALINET's paticipation in the ESA AEOLUS mission validation by performing correlative measurements as closa as possible in time to Aeolus overpasses and establish a timeframe to make observations based on the station-overpass distance, e.g., a $2 \mathrm{~h}$-period for $40 \mathrm{~km}$ distances and a $4 \mathrm{~h}$-period for $100 \mathrm{~km}$.

\section{ACKNOWLEDGEMENTS}

The authors would like to thank for the support given by ILRC 2019 committee. A.V.S., H.B. and E.L. would like to thank FAPESP for the research grants: $17 / 23810-9,13 / 50510-5,17 / 17047-0$ and 15/12793-0, respectively. F.S., D.G. and G.A. would like to thank for CNPq, F.S. was under grant numbers: 152156/18-6, 432515/18-6 and $1507116 / 17-6$. B.B would like to thank FONDCYT for research grant 11181335. C.R. would like to thank Area Metropolitana del Valle de Aburrá for the Science and Technology grant number 511/2017.

\section{REFERENCES}

[1] Antuña-Marrero, J.C., E. Landulfo, R. Estevan, B. Barja, A. Robock, E. Wolfram, P. Ristori, B. Clemesha, F. Zaratti, R. Forno, E. Armandillo, Á.E. Bastidas, Á.M. de Frutos Baraja, D.N. Whiteman, E. Quel, H.M. Barbosa, F. Lopes, E. Montilla-Rosero, and J.L. Guerrero-Rascado, LALINET: The First Latin American-Born Regional Atmospheric Observational Network. Bull. Amer. Meteor. Soc., 98, 1255-1275, (2017)
[2] A. G. Guedes, E. Landulfo, E. Montilla-Rosero, F. J.S. Lopes, J. J. Hoelzemann, J. H. Fernandez, M. P.A. Silva, R.S.S. Santos, J.L. Guerrero-Rascado, L. Alados-Arboledas, Detection of saharan mineral dust aerosol transport over brazilian northeast through a depolarization lidar, EPJ Web of Conferences, 2018

[3] J. S. Lopes, F.; Silva, J.J.; Antuña Marrero, J.C.; Taha, G.; Landulfo, E. Synergetic Aerosol Layer Observation After the 2015 Calbuco Volcanic Eruption Event. Remote Sens. 2019, 11, 195.

[4] F.J.S. Lopes, J. L. Guerrero-Rascado, J.A. Benavent-Oltra, R. Román, G.A. Moreira, M.T.A. Marques, J. J. da Silva, L.Alados-Arboledas, P. Artaxo, E. Landulfo, Rehearsal for Assessment of atmospheric optical Properties during biomass burning Events and Long-range transportation episodes at Metropolitan Area of São Paulo-Brazil (RAPEL), , EPJ Web of Conferences, 2018

[5] Gouveia, D. A.; Barja, B.; Barbosa, H. M.; Seifert, P.; Baars, H.; Pauliquevis, T.; Artaxo, P. Optical and geometrical properties of cirrus clouds in Amazonia derived from 1 year of ground-based lidar measurements. Atmospheric Chemistry and Physics, v. 17, n. 5, p. 3619-3636, 2017.

[6] E. A. Wolfram, J. Salvador, F. Orte, R. D’Elia, S. Godin-Beekmann, J. Kuttippurath, A. Pazmino , F. Goutail, C. Casiccia, F. Zamorano, N. Paes Leme, and E. J. Quel, The unusual persistence of an ozone hole over a southern mid-latitude station during the Antarctic spring 2009: a multi-instrument study, Ann. Geophys., 30, 1435-1449, 2012

[7] G. A. Moreira, F.J.S. Lopes, J.L. GuerreroRascado, J.J. Silva, A. A. Gomes, E. Landulfo, and L. Alados-Arboledas. Analyzing the Atmospheric Boundary Layer by high-order moments obtained from multiwavelenght lidar data: impact of wavelength choice. Submitted, 2019.

[8] Thomason, L. and Kremser, S., 2017, SSiRC Meeting at ISSI, SPARC Newsletter, No. 49,

July 2017 , pp. $26-29$.

[9] Wolfram, E. A., Salvador, J., Orte, F., D'Elia, R., Godin-Beekmann, S., Kuttippurath, J., Pazmiño, A., Goutail, F., Casiccia, C., Zamorano, F., Paes Leme, N., and Quel, E. J.The unusual persistence of an ozone hole over a southern mid-latitude station during the Antarctic spring 2009: a multi-instrument study,: Ann. Geophys., 30, 1435-1449, doi:10.5194/angeo-30-14352012, 2012.

[10] J. Céspedes, C. A. Melo-Luna, J. H. Reina, A first measurement of the planetary boundary layer top in santiago de cali-colombia: elastic lidar application, in: Remote Sensing of Clouds and the Atmosphere XXIII, Vol. 10786, International Society for Optics and Photonics, 2018, p.107860L 